\title{
Analisa Kinerja Pengkodean Kanal Type Reed Solomon Coding pada Kualitas Transmisi Citra
}

\author{
Baharuddin \\ Jurusan Teknik Elektro, Fakultas Teknik, Universitas Andalas \\ Corresponding author, e-mail: baharuddin@eng.unand.ac.id
}

\begin{abstract}
Abstrak - Dalam sistem telekomunikasi, data multimedia berupa audio, citra, dan video ditransmisikan ke penerima melalui sebuah kanal komunikasi. Pada sistem telekomunikasi yang menggunakan kanal komunikasi wireless, selain pengaruh redaman, gangguan yang paling dominan adalah noise dan fading. Fading dan noise dikanal akan menurunkan kinerja sistem telekomunikasi digital karena dapat menyebabkan terjadinya kesalahan pendeteksian sinyal, sehingga terjadi perubahan bit atau simbol pada sisi penerima. Dengan menerapkan teknik pengkodean kanal tipe Reed Solomon Code pada sisi pengirim dan penerima, maka dapat ditingkatkan kinerja dari sistem komunikasi digital tersebut. Melalui simulasi dalam penelitian ini, telah dianalisa pengaruh penerapan teknik pengkodean kanal Reed Solomon Code pada sistem yang dipengaruhi noise Additive White Gaussian Noise (AWGN) dan fading Rayleigh. Besarnya pengaruh penggunaan dari teknik pengkodean kanal Reed Solomon Code dapat diketahui melalui analisa Bit Error Rate (BER) dan Peak Signal to Noise Ratio (PSNR). Hasil simulasi dari penelitian ini menunjukkan bahwa adanya peningkatan perbaikan sistem dipenerima rata-rata $5 \mathrm{~dB}$ bila dibandingkan dengan tanpa menggunakan teknik pengkodean kanal Reed Solomon Code.
\end{abstract}

Kata Kunci : Reed Solomon Code, Noise AWGN, Fading Rayleigh, PSNR, BER

\begin{abstract}
In the telecommunication systems, the data like audio, image, and video are transmitted to a receiver through a communication channel. However, the presence of noise and fading in the channel will degrade its performance. The degradation may cause error on signal detection and change the bits or symbols on the receiver. By applying a RS Code channel coding technique on the transmitter and the receiver, it may improve the performance of digital communication system. The influence of employing the RS Code channel coding technique on the system with noise Additive White Gaussian Noise (AWGN) and Rayleigh fading has been analyzed through a simulation. Performance evaluation on the use of RS Code channel coding technique can be determined from the analysis of Bit Error Rate (BER) and Peak Signal to Noise Ratio (PSNR). The simulation result shows that the system is improved by $5 \mathrm{~dB}$ on the receiver compares to the system without using RS Code channel coding technique.
\end{abstract}

Keywords : Reed Solomon Code, Noise AWGN, Fading Rayleigh, PSNR, BER

\section{Pendahuluan}

Dalam sistem transmisi telekomunikasi, informasi berupa data, suara, citra dan video akan dikirim dari pemancar menuju penerima melalui sebuah kanal komunikasi. Kanal komunikasi secara real dapat berupa medium fisik (seperti dua pasang kabel, kabel koaksial, serta fiber optik yang menghubungkan antara pemancar dan penerima), maupun medium non-fisik (seperti medium udara berupa gelombang elektromagnetik yang dipancarkan dari pemancar ke penerima). Selama transmisi informasi melalui kanal komunikasi pasti akan selalu terjadi penurunan kualitas informasi. Penurunan kualitas informasi ini dapat disebabkan oleh berupa interferensi, delay spread, redaman (attenuation), derau (noise) serta timbul tenggelamnya sinyal informasi (fading) [1].

Pada medium non-fisik (kanal wireless), gangguan yang paling dominan adalah adanya multipath fading. Multipath fading terjadi karena sinyal informasi yang dipancarkan akan tersebar kesegala arah melewati medium udara. Akibatnya sinyal yang sampai dipenerima adalah penjumlahan antara sinyal informasi dari arah path 1 , path 2 , path 3 dan seterusnya. Sehingga akan didapat sinyal yang saling mengurangkan dan bahkan saling menghilangkan akibat adanya perbedaan fasa yang tiba di penerima. Pengaruh dari gangguan dominan ini dapat menyebabkan kesalahan pendeteksian pada bagian penerima 
system telekomunikasi. Misalnya akibat pengaruh dari gangguan ini, sinyal informasi yang dikirim bit " 1 " dapat berubah menjadi bit "0" yang diterima di bagian penerima begitupun sebaliknya, sehingga dengan demikian unjuk kerja sistem akan menurun di bagian penerima. Salah satu usaha yang dilakukan untuk mengatasi permasalahan dari gangguan noise dan fading yang terjadi pada kanal wireless adalah dengan menggunakan pengkodean kanal. Pada penelitian ini pengkodean kanal yang digunakan adalah type Reed Solomon (RS) Coding, ini dikarenakan atas kemampuannya mendeteksi dan mengoreksi kesalahan yang cukup tinggi, yang diakibatkan oleh noise dan fading [2]. Pengujian dilakukan dengan membandingkan sistem dengan dan tanpa menggunakan pengkodean kanal RS Coding. Evaluasi terhadap sistem perbaikan kualitas transmisi citra ini, dihitung dengan menggunakan nilai Bit Error Rate (BER) terhadap nilai Peak Signal to Noise Rasio (PSNR), dimana nilai dari BER menunjukkan seberapa banyak kesalahan pengiriman bit atau simbol yang terjadi di penerima dibandingkan dengan banyaknya bit atau simbol yang ditransmisikan (misalnya nilai BER $10^{-6}$, berarti bila bit yang ditransmisikan sebanyak 1 juta, maka kesalahan yang terjadi dibagian penerima hanya terdapat 1 bit). Sedangkan nilai PSNR menunjukkan perbandingan elemen gambar citra rekonstruksi terhadap elemen gambar citra sumber informasi [3-6].

Beberapa penelitian tentang transmisi citra melalui kanal wireless telah dilakukan antara lain oleh [1] yang menggunakan teknik diversity yang berada pada domain wavelet untuk mendapatkan citra rekonstruksi yang baik. Pada transnmisi citra ini model kanal yang digunakan adalah two-state Gilbert-Elliott channel, serta [7] yang menggunakan Turbo Codes untuk melindungi citra selama transmisi, juga [8] yang menggunakan teknik perlindungan data selama transmisi.

Pada penelitian ini digambarkan suatu simulasi yang menerapkan teknik pengkodean kanal type RS Coding. Teknik RS Coding mengacu pada [9].

\section{Tinjauan Pustaka}

\subsection{Noise AWGN}

Model kanal yang digunakan adalah Noise AWGN (Additive White Gaussian Noise). Noise ini berdistribusi normal dengan nilai rata-rata (mean) nol. Noise ini bernilai acak dan bersifat menambahkan sinyal aslinya. Bentuk persamaan pdf (probability density function) dari distribusi Gaussian adalah [2-6]:

$$
p(x)=\frac{1}{\sqrt{2 \pi} \sigma} e^{-\left(x-m_{x}\right)^{2} / 2 \sigma^{2}}
$$

dimana :

$\mathrm{x}=$ variabel Acak

$m_{x}=$ mean

$\sigma^{2}=$ varians dari variable random

\subsection{Fading Rayleigh}

Pada kanal wireless, distribusi Rayleigh secara umum dipakai untuk menggambarkan statistik perbedaan waktu dari envelope yang diterima untuk sebuah sinyal flat Fading. Fading cepat merupakan Rayleigh fading karena fading ini terdistribusi mengikuti distribusi Rayleigh, yang mempunyai fungsi kepadatan probabilitas seperti yang ditunjukkan persamaan (2) [2-6]:

$$
p\left(r_{a}\right)=\left\{\begin{array}{cc}
\frac{r_{a}}{\sigma^{2}} \exp \left(-\frac{r_{a}^{2}}{2 \sigma^{2}}\right) & \left(0 \leq r_{a} \leq \infty\right) \\
0 & \left(r_{a}<0\right)
\end{array}\right.
$$

dimana :

$$
\begin{aligned}
& \sigma=\text { tegangan rata }- \text { rata } \\
& \sigma^{2}=\text { daya rata-rata }
\end{aligned}
$$

Fungsi distribusi kumulatif menyatakan presentasi lebih kecil dari nilai $R_{a}$ tertentu, yang diperoleh dengan melakukan integral terhadap fungsi rapat peluang $p\left(r_{a}\right)$.

$P\left(R_{a}\right)=P_{r_{a}}\left(r_{a} \leq R_{a}\right)=\int_{0}^{R_{a}} p\left(r_{a}\right) d r_{a}=1-\exp \left(-\frac{R_{a}{ }^{2}}{2 \sigma^{2}}\right)$

$r_{a_{\text {mean }}}$ distribusi Rayleigh adalah :

$$
r_{a_{\text {mean }}}=E\left[r_{a}\right]=\int_{0}^{\infty} r_{a} p\left(r_{a}\right) d r_{a}=\sigma \sqrt{\frac{\pi}{2}}=1,2533 \sigma
$$

$\sigma_{r_{a}}^{2}$ merupakan varians dari distribusi Rayleigh yang mewakili daya AC pada selubung sinyal.

$$
\begin{aligned}
\sigma_{r_{a}}^{2} & =E\left[r_{a}^{2}\right]-E^{2}\left[r_{a}\right]=\int_{0}^{\infty} r_{a}^{2} p\left(r_{a}\right) d r_{a}-\frac{\sigma^{2}}{2} \\
& =\sigma^{2}\left(2-\frac{\pi}{2}\right)=0,4292 \sigma^{2}
\end{aligned}
$$

Untuk menghitung nilai tengah $r_{a}$, dapat digunakan persamaan (4). 


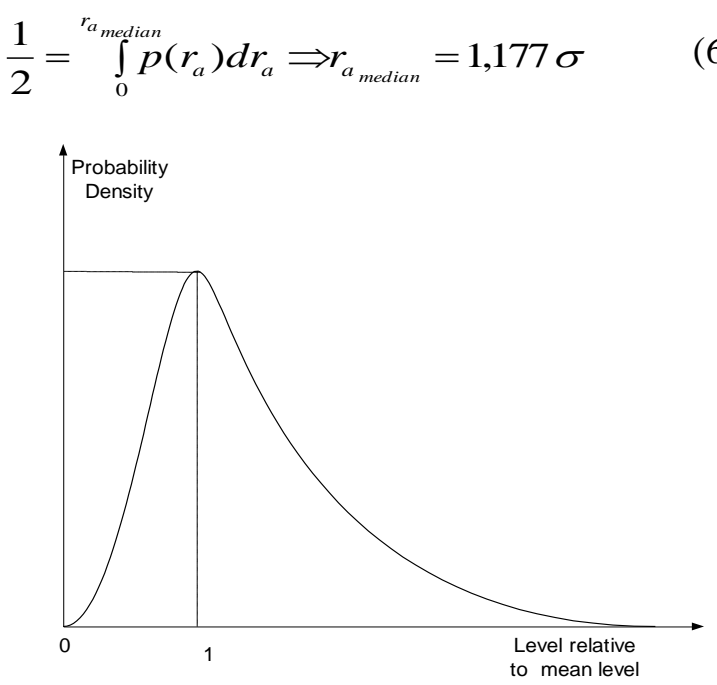

Gambar 1. Grafik pdf distribusi Rayleigh [2-6]

Jadi terdapat perbedaan nilai rata-rata dan nilai tengah sebesar 0,55 dB dalam distribusi Rayleigh. Sebagai catatan bahwa nilai tengah pada prakteknya sering digunakan, karena data fading biasanya diukur dilapangan dan kenyataannya distribusinya tidak dapat diasumsikan. Dengan penggunaan nilai tengah sebagai pengganti nilai rata-rata, maka akan mudah untuk membandingkan distribusi fading yang berbeda dan memiliki nilai tengah yang bermacam-macam. Envelope sinyal fading yang dibangkitkan merupakan proses kompleks Gaussian yang mempunyai bagian real yang independen dengan bagian imajiner-nya. Pada Gambar 1 ditunjukkan grafik pdf (Probability Density Function) dari suatu distribusi Rayleigh.

\subsection{Kode Reed-Solomon}

Kode Reed Solomon merupakan kode blok yang mampu mendeteksi dan mengoreksi kesalahan. Kode blok ini dapat digunakan untuk meningkatkan unjuk kerja sistem komunikasi ketika peralatan yang lain tidak mungkin untuk diterapkan, seperti menambah daya pemancar atau penggunaan demodulator yang komplek.[2]

Kode Reed-Solomon (RS) adalah subclas dari Bose-Chadhuri-Hocquenghem (BCH) nonbiner. Pada kode RS setiap blok dipandang sebagai $k$ simbol yang setiap simbolnya mempunyai $m$ bit. Kode RS ditulis dengan $\operatorname{RS}(n, k)=\operatorname{RS}\left(2^{m}-1,2^{m}-1\right.$ $2 t$ ), yang berarti bahwa untuk $k$ simbol, di mana dalam 1 simbol terdapat $m$ bit data biner, akan dikodekan menjadi $n$ simbol, dan kemampuan koreksinya $(t)=(n-k) / 2[2-9]$.

\subsubsection{Enkoder Reed-Solomon}

Bentuk umum dari kode RS dapat dituliskan dengan $(n, k)=\left(2^{m}-1,2^{m}-1-2 t\right)$, di mana $n-k=2 t$ adalah banyaknya simbol parity dan $t$ merupakan kemampuan untuk mengoreksi simbol error. Sedangkan bentuk generator polinomial dari kode RS dapat dituliskan sebagai berikut: [10].

$$
g(x)=g_{0}+g_{1} x+g_{2} x^{2}+\ldots+g_{2 t-1} x^{2 t-1}+x^{2 t}
$$

Derajat dari generator polinomial sama dengan banyaknya simbol parity yang ditambahkan yaitu $2 t$. Sehingga akar dari generator polinomial, yang dilambangkan dengan $\alpha$, mempunyai derajat yang sama. Akar-akar dari $\mathrm{g}(\mathrm{x})$ dapat dituliskan sebagai $\alpha, \alpha^{2}, \alpha^{3}, \ldots, \alpha^{2 t}$. Sebagai contoh kode RS $(7,3)$, dengan $n=7$ dan $k=3$, mempunyai kemampuan untuk mengoreksi error simbol $2 t=n-k=4$, maka kode tersebut memunyai 4 akar. Generator polinomialnya dapat dituliskan sebagai berikut [12]:

$$
\begin{aligned}
& g(x)=(x-\alpha)\left(x-\alpha^{2}\right)\left(x-\alpha^{3}\right)(x-\alpha 4) \\
& =\left(x^{2}-\left(\alpha-\alpha^{2}\right) x+\alpha^{3}\right)\left(x^{2}-\left(\alpha^{3}+\alpha^{4}\right) x+\alpha^{7}\right) \\
& =\left(x^{2}-\alpha^{4} x+\alpha^{3}\right)\left(x^{2}-\alpha^{6} x+\alpha^{7}\right) \\
& =x^{4}-\left(\alpha^{4}+\alpha^{3}\right) x^{3}+\left(\alpha^{3}+\alpha^{10}+\alpha^{6}\right) x^{2}-\left(\alpha^{4}-\alpha^{9}\right) x+\alpha^{3} \\
& =x^{4}-\alpha^{3} x^{3}+\alpha^{0} x^{2}-\alpha^{1} x+\alpha^{4}
\end{aligned}
$$

Berdasarkan derajat polinomialnya dari rendah ke tinggi dan dalam field biner $+1=-1$, maka generator $\mathrm{g}(\mathrm{x})$ dapat dituliskan dengan: [8].

$$
g(x)=\alpha^{3}+\alpha^{1} x+\alpha^{0} x^{2}+\alpha^{3} x^{3}+x^{4}
$$

Untuk pembentukan polinomial codeword nya dilakukan dengan persamaan:

$$
U(x)=p(x)+x^{n-k} m(x)
$$

di mana

$U(x) \quad=$ codeword yang dibentuk

$m(x) \quad=$ simbol nformasi yang akan dikodekan $p(x)=$ simbol parity

Simbol parity didapatkan dari sisa pembagian antara perkalian simbol informasi yang akan dikodekan dan polinomial $x^{n-k}$ dengan generator polinomial $g(x)$, yang secara matematis $p(x)$ dapat dituliskan dengan persamaan [2-12]:

$$
p(x)=x^{n-k} m(x) \bmod g(x) \text {. }
$$

\subsubsection{Dekoder Reed-Solomon}

Pada RS dekoder, codeword yang diterima mempunyai persamaan [2-7]:

$$
r(x)=U(x)+e(x)
$$


di mana

$\mathrm{r}(\mathrm{x})$ = codeword yang diterima

$\mathrm{r}(\mathrm{x})$ akan bernilai sama dengan $\mathrm{U}(\mathrm{x})$ pada

saat codeword yang diterima tidak mengalami error $(\mathrm{e}(\mathrm{x})=0)$.

$\mathrm{U}(\mathrm{x})=$ codeword yang dikirimkan

$\mathrm{e}(\mathrm{x})=$ error

Langkah pertama yang dilakukan dekoder RS untuk mendekodekan data yang diterima, yaitu menghitung sindrom (S). Sindrom didapatkan dengan cara memasukkan akar-akar generator polinomialnya ke dalam codeword yang diterima. Penghitungan sindrom dapat dituliskan seperti pada persamaan (12) [17]:

$$
S_{i}=r(x)=r\left(\alpha^{i}\right)
$$

di mana $\mathrm{i}=1,2, \ldots, \mathrm{n}-\mathrm{k}$

Jika sindrom yang dihasilkan sama dengan nol maka codeword yang diterima tidak mengalami kesalahan, sedangkan apabila tidak sama dengan nol, maka dapat diartikan bahwa codeword yang diterima mengalami kesalahan, sehingga akan dilakukan langkah berikutnya, yaitu:

a. Mencari lokasi error

Lokasi error yang dilambangkan dengan $\sigma(\mathrm{x})$ mempunyai persamaan polinomial error locator sebagai berikut [7]:

$$
\sigma(x)=1+\sigma_{1} x+\sigma_{2} x^{2}+\ldots+\sigma_{v} x^{v}
$$

di mana $v$ menunjukkan error yang terjadi sampai pada lokasi ke $x^{v}$

Nilai-nilai dari $\sigma_{1}, \sigma_{2}, \ldots, \sigma^{\mathrm{v}}$ dapat dicari menggunakan matrik seperti yang terlihat pada persamaan (14), di mana sindrom pertama dilakukan untuk memprediksi sindrom berikutnya [9-14].

$$
\left[\begin{array}{cccccc}
S_{1} & S_{2} & S_{3} & \ldots & S_{t-1} & S_{t} \\
S_{2} & S_{3} & S_{4} & \ldots & S_{t} & S_{t+1} \\
\cdot & & & & & \\
\cdot & & & & & \\
S_{t-1} & S_{t} & S_{t+1} & \ldots & S_{2 t-3} & S_{2 t-2} \\
S_{t} & S_{t+1} & S_{t+2} & \ldots & S_{2 t-2} & S_{2 t-1}
\end{array}\right]\left[\begin{array}{c}
\sigma_{t} \\
\sigma_{t-1} \\
\cdot \\
\cdot \\
\sigma_{2} \\
\sigma_{1}
\end{array}\right]=\left[\begin{array}{c}
-S_{t+1} \\
-S_{t+2} \\
\cdot \\
\cdot \\
-S_{2 t-1} \\
-S_{2 t}
\end{array}\right]
$$

Setelah nilai-nilai $\sigma$ pada persamaan (13) dapat ditentukan, maka terbentuklah persamaan untuk $\sigma(\mathrm{x})$. Lokasi error dapat diketahui dengan cara mensubstitusikan akarakar generator polinomial ke dalam variabel $\mathrm{x}$. Lokasi error $(\beta)$ terjadi pada saat $\sigma(\mathrm{x})=0$. b. Nilai error

Setelah lokasi error diketahui, maka nilai error dapat ditentukan dengan menggunakan persamaan (15) [2, 9].

$$
S_{i}=e_{i}(\beta)=\sum_{a=1}^{t} e_{a} \beta_{a}
$$

di mana $\mathrm{i}=1,2, \ldots,(\mathrm{n}-\mathrm{k}) / 2=1,2, \ldots, \mathrm{t}$

\subsection{Transformasi Wavelet}

Transformasi wavelet merupakan salah satu metode pengkodean sumber (kompresi) yang mengkonsentrasikan koefisien ke sejumlah kecil pixel. Berdasarkan sifatnya, transformasi ini dapat dikategorikan sebagai pengkodean transformasi (transformation coding), pengkodean subband (subband coding), dan pengkodean piramid (pyramid coding) [12].

Analisis wavelet merepresentasikan sinyal ke daerah skala-waktu (time-scale region) yang tentunya berbeda dengan analisis Fourier yang bekerja pada daerah frekuensi, ataupun Shannon yang bekerja pada daerah waktu. Perbedaan ini dapat dilihat pada Gambar 2 [4-11]. Sebuah wavelet adalah bentuk gelombang dengan durasi terbatas yang mempunyai nilai rata-rata nol. Wavelet sangat berbeda dengan gelombang sinusoidal, yang merupakan basis dari analisis Fourier, yang memiliki durasi tak terhingga.

Analisis Fourier memecah sebuah sinyal menjadi gelombang-gelombang sinusoidal dengan berbagai frekuensi. Sedangkan analisis wavelet memecah sebuah sinyal menjadi berbagai versi tertranslasi dan terskala dari induk wavelet (mother wavelet).
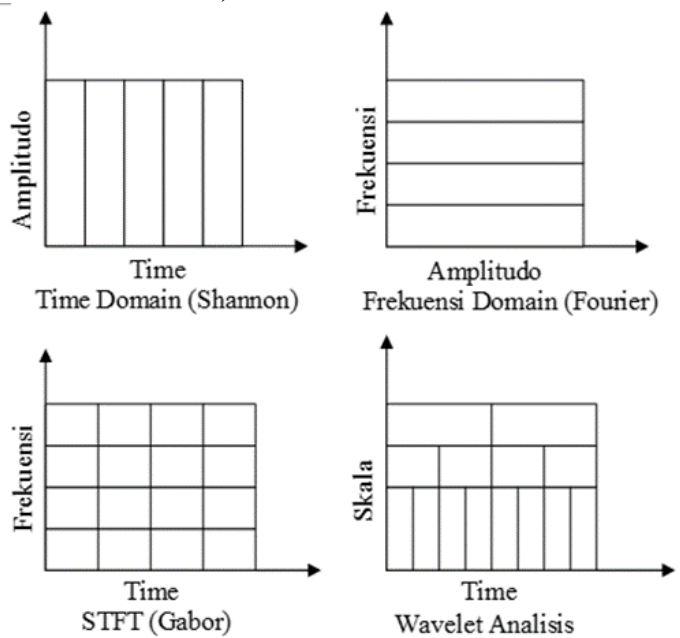

Gambar 2. Perbandingan beberapa metode analisa sinyal [11]. 


\section{Metoda}

Metode penelitian yang digunakan dalam penelitian ini adalah metode eksperimental. Penelitian eksperimental merupakan observasi dibawah kondisi buatan dimana kondisi tertentu dirancang dan diatur oleh peneliti serta penelitian dilakukan dengan melakukan manipulasi terhadap objek penelitian dengan adanya kontrol terhadap objek tersebut [15].

\subsection{Sampel Penelitian}

Sampel penelitian yang digunakan adalah citra digital grayscale dengan kedalaman 8 bit dengan nama file Lena.tif. Sampel tersebut merupakan standar internasional untuk penelitian citra. Citra grayscale digunakan untuk penelitian ini karena untuk citra grayscale tingkat komputasi yang dibutuhkan tidak terlalu tinggi dibanding citra RGB dan pada dasarnya dalam proses transmisi citra kedua jenis citra tersebut mempunyai karakteristik yang sama. Citra sampel mempunyai kedalaman 8 bit, yang berarti bahwa untuk masing-masing pixel pada citra sampel diwakili oleh nilai 8 bit yang bervariasi dari $0-255$ sesuai dengan karakteristik citra tersebut.

\subsection{Desain Penelitian}

Penelitian dilakukan dengan merancang sebuah sistem transmisi citra seperti gambar di bawah ini:

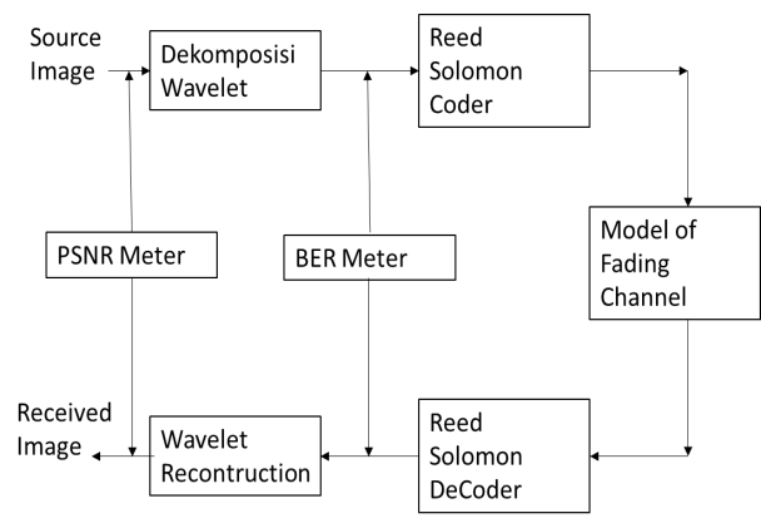

Gambar 3. Blok diagram transmisi citra

\subsection{Simulasi Kanal AWGN dan Fading Rayleigh}

Dari model tersebut diketahui bahwa $y(t)$ adalah sinyal yang dikirim berupa sinyal persegi yang sudah termodulasi BPSK dimana kanal telah terdapat fading yang berdistribusi Rayleigh. Pengaruh dari fading ini akan merusak bentuk sinyal pada masing-masing kanal. Kemudian sinyal-sinyal yang terkena fading itu akan dipengaruhi pula oleh noise Gaussian $n(t)$. Sinyal yang terkena fading dan noise ini selanjutnya masuk ke rangkaian matched filter integrated and dump agar didapatkan sinyal dengan performansi yang lebih baik sehingga sinyal ini lebih menyerupai sinyal aslinya.

Noise yang dibangkitkan pada sistem ini berdistribusi normal dengan mean $\mu$ adalah nol dan varian $\sigma^{2}$ sebesar $N o / 2$.

$$
n_{k}(t) \sim N\left(0, \frac{N o}{2}\right)
$$

Besarnya varian dipengaruhi oleh harga $N o$ yang bervariasi sesuai dengan besarnya $S N R$ (Signal to Noise ratio) dan besar energi perbitnya $E b$. Hubungan dari parameter-parameter ini ditentukan dengan persamaan :

$$
S N R=\frac{E b}{N O}
$$

Selain itu kanal juga dipengaruhi oleh fading yang memiliki distribusi Rayleigh. Envelope sinyal fading yang dibangkitkan merupakan proses kompleks gaussian yang mempunyai bagian real yang independen dengan bagian imajinernya. Pada kanal radio mobil, distribusi Rayleigh secara umum dipakai untuk menggambarkan statistik perbedaan waktu dari envelope yang diterima untuk sebuah sinyal flat fading. Fading cepat merupakan Rayleigh fading karena fading ini terdistribusi mengikuti distribusi Rayleigh.

Fading merupakan karakteristik utama dalam propagasi radio bergerak. Fading dapat didefenisikan sebagai perubahan fasa, polarisasi dan level dari suatu sinyal terhadap waktu. Defenisi dasar dari fading yang paling umum adalah yang berkaitan dengan mekanisme propagasi yang melibatkan refraksi, refleksi, difraksi, hamburan dan redaman gelombang radio. Dari segi kualitas, keberadaan fading dapat dirasakan sebagai timbul tenggelamnya suara yang terdengar di penerima. Sinyal fading $r(t)$ merupakan gabungan dua komponen yaitu $r_{l}(t)$ dan $r_{o}(t), r_{l}(t)$ disebut fading lambat, sedangkan $r_{o}(t)$ disebut fading cepat dengan persamaan :

$$
r(t)=r_{l}(t)-r_{o}(t)
$$

sedang fading cepat diperoleh dari :

$$
r_{o}(t)=r(t)-r_{l}(t)
$$

Fading lambat adalah rata-rata sinyal fading $r_{l}(t)$ yang juga disebut dengan local mean. Fading lambat disebabkan adanya perubahan konfigurasi alam antara base station dengan unit bergerak yang akan menyebabkan fluktuasi path loss 
(redaman lintasan) akibat efek bayangan dari penghalang alam. Fading lambat sering disebut dengan shadowing. Fading cepat sering disebut juga dengan multipath fading. Penyebab utama dari fading ini karena adanya lintasan ganda (multipath) akibat dipantulkannya gelombang oleh benda-benda seperti rumah, gedung, kendaraan, pohon dan benda-benda lain disekitar personal station yang menyebabkan sinyal menempuh suatu lintasan dari pemancar ke penerima. Selain itu Dengan adanya tambahan noise maka bentuk sinyal akan semakin rusak. Tipe fading ini merupakan tipe yang paling umum terjadi.

Karena perbedaan panjang lintasan yang ditempuh oleh lintasan pantul dan lintasan langsung, maka akan menyebabkan perbedaan amplitudo dan fasa dari kedua sinyal tersebut ketika diterima mobile station (MS). Dalam keadaan yang ekstrim dimana sinyal sama dan beda fasa $180^{\circ}$, maka sinyal akan saling meniadakan atau sinyal total adalah nol, sebaliknya apabila fasanya sama, maka sinyal merupakan jumlah dari kedua sinyal yang datang tersebut.

\subsection{Variabel Penelitian}

Variabel-variabel yang digunakan pada penelitian berdasarkan klasifikasinya, adalah sebagai berikut:

- Variabel independen, yang merupakan variabel yang dapat dimanipulasi. Variabel independen yang digunakan dalam penelitian ini adalah bit per pixel dan SNR.

- Variabel dependen, yang berubah berdasarkan perubahan nilai variabel independen. Variabel dependen yang digunakan dalam penelitian adalah PSNR dan BER

\subsection{Teknik Analisis Sistem}

Kinerja sistem yang disimulasikan dianalisis dengan menggunakan variabel dependen PSNR (Peak Signal to Noise Ratio). PSNR dapat dirumuskan [14] :

$$
P S N R=10 \bullet \log _{10} \frac{255^{2}}{\frac{1}{N} \sum_{i} \sum_{j}(p(i, j)-\hat{p}(i, j))^{2}}
$$

Dimana $p(i, j)$ merupakan nilai piksel citra yang asli, $\hat{p}(i, j)$ merupakan nilai piksel citra rekonstruksi, dan $N$ merupakan ukuran citra. Kinerja sistem juga dianalisis dengan BER (Bit Error Rate) dengan rumus [15]:

$$
B E R=\frac{n}{N}
$$

Dengan : $\quad n=$ jumlah bit salah yang diterima

$\mathrm{N}=$ jumlah bit yang diterima

\section{Hasil dan Pembahasan}

Hasil penelitian tentang perbandingan nilai BER dan PSNR pada transmisi citra dengan dan tanpa menggunakan teknik pengkodean kanal tipe Reed Solomon Coding pada citra Lena.tif dengan rasio kompresi 0.6 bpp dapat dilihat pada Tabel 1 .

Tabel 1. Perbandingan nilai BER dan PSNR transmisi citra dengan dan tanpa teknik pengkodean kanal Reed Solomon Coding pada citra Lena.tif

\begin{tabular}{|c|c|c|c|c|}
\hline $\begin{array}{c}\text { SNR } \\
(\mathrm{dB})\end{array}$ & BER & $\begin{array}{c}\text { PSNR } R S \\
\text { Code } \\
(\mathrm{dB})\end{array}$ & BER & $\begin{array}{c}\text { PSNR } \\
\text { Tanpa RS } \\
\text { Code } \\
(\mathrm{dB})\end{array}$ \\
\hline 10 & 0.0187 & 12.4001 & 0.0204 & 10.5715 \\
12 & 0.0165 & 14.0428 & 0.0175 & 12.1145 \\
14 & 0.0148 & 17.4349 & 0.0153 & 13.9666 \\
16 & 0.0134 & 20.7588 & 0.0147 & 15.8829 \\
18 & 0.0122 & 23.3669 & 0.0134 & 18.5454 \\
20 & 0.0114 & 25.8941 & 0.0126 & 20.7588 \\
22 & 0.0106 & 28.2022 & 0.0117 & 22.1261 \\
24 & 0.0103 & 32.2060 & 0.0109 & 24.0748 \\
26 & 0.0097 & 33.7357 & 0.0106 & 26.0536 \\
28 & 0.0093 & 33.8118 & 0.0098 & 28.2022 \\
30 & 0.0091 & 34.5035 & 0.0097 & 31.2929 \\
\hline
\end{tabular}

Grafik perbandingan antara BER dan PSNR dari hasil simulasi dengan sampel citra lena ini dapat dilihat pada Gambar 4.

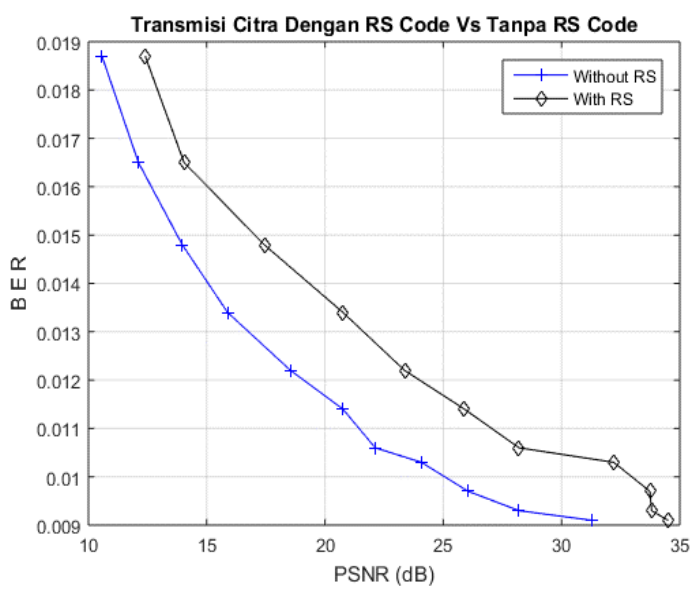

Gambar 4 . Perbandingan BER dan PSNR sistem secara grafik berdasarkan hasil pada Tabel 1. 
Pada Gambar 5 ditunjukkan perbandingan citra rekonstruksi Lena.tif antara sistem dengan dan tanpa menggunakan teknik pengkodean kanal RS coding dengan rasio 0.6 bpp pada SNR $20 \mathrm{~dB}$.

\begin{tabular}{|l|l|}
\hline Tanpa RS Code & \multicolumn{1}{|c|}{ Dengan RS Code } \\
\hline & \\
&
\end{tabular}

Gambar 5. Perbandingan citra rekonstruksi Lena pada sistem dengan dan tanpa teknik pengkodean kanal RS coding dengan rasio kompresi $0,6 \mathrm{bpp}$ pada SNR $20 \mathrm{~dB}$.

Simulasi unjuk kerja sistem transmisi citra dengan menggunakan teknik pengkodean kanal RS coding dilakukan berdasarkan blok diagram pada Gambar 3. Analisis dilakukan berdasarkan hasil dari simulasi yang telah dilakukan. Rasio kompresi yang diberikan adalah 0,6 bpp. Berikut ini merupakan tabel perbandingan nilai SNR, BER, dan PSNR citra Lena pada rasio kompresi 0,6 bpp.

Berdasarkan hasil pada Tabel 1 dan grafik Gambar 4 terlihat bahwa perbandingan kinerja dari sistem menggunakan dengan dan tanpa teknik pengkodean kanal type RS coding rata-rata menghasilkan peningkatan kinerja sistem transmisi citra $5 \mathrm{~dB}$ pada setiap nilai SNR yang diberikan. Representasi dari hasil penelitian ini dapat dilihat pada pada Gambar 5 yang mewakilkan penilaian secara subjektif pada nilai SNR 20 dB. Pada kedua gambar tersebut terlihat jelas perbedaan sistem tanpa menggunakan RS Code yang mengalami blur, sedangkan sistem dengan menggunakan RS Code terlihat tanpa blur.

\section{Kesimpulan}

Berdasarkan hasil penelitian yang dilakukan, maka dapat disimpulkan bahwa setiap kenaikan SNR berimplikasi pada penurunan BER, dan juga meningkatkan nilai PSNR citra rekonstruksi. Semakin besar nilai SNR, maka nilai PSNR akan bertambah besar. Perbaikan unjuk kerja transmisi citra akan mengalami peningkatan dengan menggunakan pengkodean kanal RS Code dengan rata-rata sebesar $5 \mathrm{~dB}$ pada setiap kenaikan SNR, bila dibandingkan dengan tanpa menggunakan RS Code.

\section{Ucapan Terima Kasih}

Terima kasih disampaikan kepada Jurusan Teknik Elektro dan Fakultas Teknik Universitas Andalas yang telah memberikan dana penelitian DIPA Fakultas Teknik dengan nomor kontrak: 090/UN.16.09.D/PL/2017.

\section{Daftar Pustaka}

[1] Liane C. Ramac dan Pramod K. Varshney, "A Wavelet Domain Diversity Method for Transmission of Images over Wireless Channels", IEEE Journal On Selected Areas In Communication, Vol. 18, pp. 891-898 No. 6, 2000.

[2] Sklar, Bernard. 1997. Rayleigh Fading Channels in Mobile Digital Communication Systems. IEEE Communication Magazine, Juli 1997.

[3] Baharuddin, "Peningkatan Kualitas Transmisi Citra dengan Menggunakan Teknik Diversity Combining Metode Equal Gain Diversity ", Proceedings, No.: ISBN: 979.756-077-7, pp. 121 - 126, 2005.

[4] Baharuddin, "Transmisi Citra dengan Teknik Diversity pada Kanal Wireless", Thesis, ITS, 2005.

[5]. Baharuddin, "Peningkatan Unjuk Kerja Transmisi Citra Terkompresi Spiht Menggunakan Teknik Diversity Equal Gain Combining Pada Daerah Frekuensi Radio" Jurnal Saintek Vol X Nomor 1. Terakreditasi, No. ISSN 1410-8070, pp. 95106, 2007.

[6] Baharuddin, "Analisa Unjuk Kerja Peningkatan Transmisi Citra Pada Kanal Wireless Menggunakan Teknik Diversity Selection Combining" Jurnal JNTE ISSN: 2302-2949 Vol. 5 No. 2, 2016.

[7] Thomos Nikolaos, Boulgouris Nikolaos V, dan Strinzis Michael G, "Wireless Image Transmission Using Turbo Codes and Optimal Unequal Error Protection", IEEE 
Trans On Image Processing, Vol. 14 pp. 643-650 No.11, 2005.

[8] P.G. Sherwood dan K. Zeger, "Error Protection for Progressive Image Transmission over Memoryless and Fading Channels", IEEE Trans. Commun., vol.46, pp. 1555-1559, 1998.

[9] Irsyad dan Baharuddin, "Simulasi unjuk kerja pengkodean kanal tipe reed solomon dalam pengkoreksian Error informasi", Tugas Akhir, Universitas Andalas, 2007

[10] Kou, Weidong. "Digital Image Compression Algorithms and Standards". Kluwer Academic Publisher. 1995.

[11] Hourani, Hafeth, " An Overview of Diversity Techniques in Wireless Communication System", Helsinki University of Technology Communication Lab 2005.

[12] E. N. Gilbert, "Capacity of a burst-noise channel," Bell Syst. Tech. J., pp. 1253-1265, 1960 .
[13] E. O. Elliott, "Estimates of error rates for codes on burst error channels," Bell Syst. Tech. J., vol. 42, p. 1977, 1963.

[14] Said, Amir dan Pearlman, William A. "A New, Fast, and Efficient Image Codec Based on Set Partitionung in Hierarchical Trees". IEEE Transactions on Circuits and Systems for Video Technology, Vol 6, No. 3., 1996.

[15] Nazir, Mohammad, "Metode Penelitian", Jakarta: Ghalia Indonesia 1983.

\section{Biodata Penulis}

Baharuddin adalah staf pengajar Jurusan Teknik Elektro, Fakultas Teknik Universitas Andalas Padang. Lulus Program Sarjana pada tahun 1993 pada Bidang Teknik Telekomunikasi dan Elektronika, Jurusan Teknik Elektro, Fakultas Teknik Universitas Hasanuddin. Lulus program Master pada Bidang Teknik Telekomunikasi Multimedia di ITS Surabaya tahun 2005. 